cơ này và cơ trán, xuyên qua cơ trán, đi trong lớp mõ dưới da. Động mạch trên ổ mắt chia trung bình 2,5 nhánh (từ 2-4 nhánh).

Trong NC của chúng tôi, ĐM trên ổ mắt đi trong cơ trán trung bình 14,88 $\pm 9,16 \mathrm{~mm}$, đa số nằm trong khoảng từ $10-20 \mathrm{~mm}$, chiếm tỷ lệ 45,2\%. Theo Erdogmus (2007), chiều dài đoạn ĐM trên ổ mắt đi trong cơ trán là $20 \mathrm{~mm}$ trong 2 trường hợp (5,3\%), $20-30 \mathrm{~mm}$ trong 20 trường hợp $(52,6 \%)$ và $30-40 \mathrm{~mm}$ trong 16 trường hợp $(42,1 \%)[8]$. Chiều dài động mạch trên ổ mắt

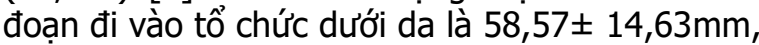
trong đó, đa số trên 50 mm, chiếm tỷ lệ 77,4\%. Cũng theo Erdogmus (2007), ĐM này nằm gần các mô dưới da trong vòng $40 \mathrm{~mm}$ tại vị trí bờ trên ổ mắt trong 3 trường hợp $(7,9 \%), 40$ $50 \mathrm{~mm}$ trong 17 trường hợp $(44,7 \%)$ và $50-60$ $\mathrm{mm}$ trong 18 trường hợp $(47,4 \%)$ [8]. Kết quả này tương đương với NC của chúng tôi. Các ĐM TDN và ĐM trên ổ mắt có thể quan sát tốt khi phẫu tích, và chúng tạo vòng nối với ĐM trên ròng rọc trên cùng bên.

\section{KẾT LUẬN}

- 90,32\% tiêu bản có ĐM trên ròng rọc, $100 \%$ tiêu bản có ĐM trên ổ mắt.

- Đường kính trung bình động mạch trên ổ mắt là $1,02 \pm 0,25 \mathrm{~mm}$. Đường kính trung bình của động mạch trên ròng rọc là $0,96 \pm 0,20 \mathrm{~mm}$.

- Khoảng cách từ ĐM trên ồ mắt tới đường giữa tại bờ trên cung mày là $24,99 \pm 5,41 \mathrm{~mm}$. Khoảng cách trung bình từ ĐM trên ròng rọc đến đường giữa tại bờ trên cung mày là 19,16 $\pm 7,49$ $\mathrm{mm}$. Khoảng cách trung bình từ ĐM trên ổ mắt đến góc mắt trong tại bờ trên cung mày là 13,54 $\pm 5,13 \mathrm{~mm}$. Khoảng cách trung bình từ ĐM trên ròng rọc đến góc mắt trong tại bờ trên cung mày là $4,75 \pm 3,75$.

- Chiều dài ĐM trên ổ mắt đi vào cơ trán trung bình là $14,88 \pm 9,16 \mathrm{~mm}$. Chiều dài trung bình động mạch trên ròng rọc đi vào cơ trán là $9,63 \pm 5,18 \mathrm{~mm}$. Chiều dài động mạch trên ổ mắt đoạn đi vào tổ chức dưới da là $58,57 \pm 14,63$ $\mathrm{mm}$. Chiều dài động mạch trên ròng rọc đoạn đi vào tổ chức dưới da là $31,39 \pm 13,92 \mathrm{~mm}$.

\section{TÀI LIÊU THAM KHẢO}

1. IT Jackson (2004), "Midline forehead flaps in nasal reconstruction". European Journal of Plastic Surgery, 27(3), pp. 105-113.

2. M. S. Álagöz, T. Işken, C. Sen. et al. (2008), "Three-dimensional nasal reconstruction using a prefabricated forehead flap: case report". Aesthetic Plast Surg, 32(1), pp. 166-71.

3. W. G. Kleintjes (2007), "Forehead anatomy: arterial variations and venous link of the midline forehead flap". J Plast Reconstr Aesthet Surg, 60(6), pp. 593-606.

4. L. Y. Cong, S. H. Lee, T. Tansatit. et al. (2016), "Topographic Anatomy of the Inferior Medial Palpebral Artery and Its Relevance to the Pretarsal Roll Augmentation". Plast Reconstr Surg, 138(3), pp. 430e-436e.

5. L. Agorgianitis, E. Panagouli, G. Tsakotos. et al. (2020), "The Supratrochlear Artery Revisited: An Anatomic Review in Favor of Modern Cosmetic Applications in the Area". Cureus, 12(2), pp. e7141.

6. Kevin A. Shumrick, Timothy L. Smith (1992), "The Anatomic Basis for the Design of Forehead Flaps in Nasal Reconstruction". Archives of Otolaryngology-Head \& Neck Surgery, 118(4), pp. 373-379.

7. Z. Potparić, K. Fukuta, L. B. Colen. et al. (1996), "Galeo-pericranial flaps in the forehead: a study of blood supply and volumes". $\mathrm{Br} \mathrm{J}$ Plast Surg, 49(8), pp. 519-28.

8. S. Erdogmus,F. Govsa (2007), "Anatomy of the supraorbital region and the evaluation of it for the reconstruction of facial defects". J Craniofac Surg, 18(1), pp. 104-12.

\title{
ĐÁNH GIÁ KẾT QUẢ PHẪU THUẬT ĐÎ̀̀U TRI HẸP ỐNG SỐNG THẮT LƯNG TẠI BỆNH VIỆN TRUNG ƯƠNG THÁI NGUYÊN
}

\section{TÓM TẮT}

Mục tiêu: Đánh giá kết quả điều trị hẹp ống sống thắt lửng bằng bằng phẫu thuật giải phóng chèn ép, nẹp vít qua cuống sống và hàn xương liên thân đốt lối

*Trường Đại học Y Dược Thái Nguyên

Chịu trách nhiệm chính: Nguyễn Vũ Hoàng:

Email: drvantu.ngtk@gmail.com

Ngày nhận bài: 14/10/2021

Ngày phản biên khoa hoc: 15/11/2021

Ngày duyệt bài: 19/12/2021

\section{Nguyễn Văn Tú*, Nguyễn Vũ Hoàng*}

sau tại Bệnh viện trung ương Thái Nguyên. Đối tượng và phướng pháp: 43 bệnh nhân hẹp ống sống thắt lưng-cùng đã được chẩn đoán xác định và phẫu thuật tại Bệnh viện trung ương Thái Nguyên từ 01/2019 đến 12/2020. Phương pháp nghiên cứu: Nghiên cứu mô tả, hồi cứu. Kết quả: Giới: Nam $11(25,6 \%)$, nữ $32(74,4 \%)$. Tuổi $56,53 \pm 11,79$, lớn nhất là 79 tuổi, nhỏ nhất là 31 tuổi. Triệu chứng lâm sàng: Có 8 ca $(18,6 \%)$ chỉ có đau lưng, 35 ca $(81,4 \%)$ đau lưng lan xuống chân, dấu hiệu đau cách hồi thân kinh gặp ở 32 ca $(74,4 \%)$, co cứng cơ cạnh sống 36 ca $(83,7 \%)$. Hình ảnh MRI: phân loại hẹp nhẹ $8 \mathrm{ca}$ 
$(18,6 \%)$, hẹp vừa 22 ca $(51,2 \%)$, hẹp nặng 13 ca $(30,2 \%)$; tầng hẹp chủ yếu là L4-L5 $(76,7 \%)$. Kết quả: tốt 33 ca $(76,8 \%)$, trung bình 9 ca $(20,9 \%)$, xấu 1 ca $(2,3 \%)$. Kết luận: Điều trị hẹp ống sống thắt lưngcùng bằng bằng phẫu thuật giải phóng chèn ép, nẹp vít qua cuống sống và hàn xương liên thân đốt lối sau đạt kết quả thành công cao, tỷ lệ biến chứng sau mổ thấp, không có tử vong sau mô.

Tư khóa: Hẹp ống sống thắt lưng, Phẫu thuật hàn xương liên thân đốt lối sau.

\section{SUMMARY}

EVALUATE THE RESULTS OF SURGICAL TREATMENT OF LUMBAR SPINAL STENOSIS IN THAI NGUYEN NATIONAL HOSPITAL

Objective: Evaluate the result of surgical treatment of lumbar spinal stenosis at Thai Nguyen National Hospital by posterior approach with screw fixation. Subjects and methods: 43 patients with degennerative lumbar spinal stenosis were operated at Thai Nguyen National Hospital from 01/2019 to 12/2020. Research Methodology: Descriptive, retrospective research. Results: Gender: Male $11(25,6 \%)$, female $32(74,4 \%)$. Age $56.53 \pm 11,79$, maximum age 79 , minimum age. Clinical symptoms: Radicular pain 35 cases $(81,4 \%)$, Low back pain 43 cases $(100 \%)$, Neurologic claudication pain 32 cases $(74,4 \%)$, paraspinal muscles spasm 36 cases $(83,7 \%)$. MR-Images: mild stenosis 8 cases $(18,6 \%)$, moderate stenosis 22 cases $(51,2 \%)$, severe stenosis 13 cases $(30,2 \%)$, mainly level L4-L5 (76,7\%). Results: good 33 cases $(76,8 \%)$, moderate 9 cases $(20,9 \%)$, poor 1 case $(2,3 \%)$. Conclusion: Posterior lumbar interbody fusion for the treatment of degennerative lumbosacral spinal stenosis achieved high success, the rate of complications is low, no mortality after surgery.

Keywords; Lumbar spinal stenosis, Posterior lumbar interbody fusion.

\section{I. ĐĂT VẤN ĐỀ}

Hẹp ống sống thắt lưng là một bệnh lý với bản chất là sự giảm chu vi quá giới hạn bình thường của ống sống gây chèn ép các cấu trúc thần kinh và mạch máu bên trong ông sống. Triệu chứng chính của bệnh là đau lưng, tê chân và dấu hiệu đau cách hồi thần kinh, yếu chân [3]. Mặc dù không trực tiếp đe dọa tính mạng của người bệnh, nhưng hẹp ống sống với tác động về thần kinh ngoại biên lại có những ảnh hưởng đến sinh hoạt hằng ngày và chất lượng sống của bệnh nhân. Trong vân đề điều trị HOSTL, thì phẫu thuật giải phóng chèn ép được thừa nhận là giải pháp có tính ưu việt khi điều trị nội khoa thất bại. Có nhiều loại hẹp và hep do nhiều nguyên nhân khác nhau. Tùy theo mối loại hẹp mà phương pháp điều trị phẫu thuật có khác nhau. Phương pháp phẫu thuật giải ép và cố định cột sống thắt lưng có ghép xương liên thân đốt là phương pháp được áp dụng tại nhiều bệnh viện trong nước và khá phổ biến tại Bệnh viện
Trung ương Thái Nguyên. Để góp phần nâng cao chất lượng chẩn đoán và điều trị bệnh lý này chúng tôi tiến hành nghiên cứu đề tài: "Kết quả phẫu thuật điều trị hẹp ống sống thắt lưng sau tại Bệnh viện Trung ương Thái Nguyên" nhằm mục tiêu: Đánh giá kêt quả điều trị hẹp ống sống thắt lưng bằng phẫu thuật giải phóng chèn ép, nẹp vít qua cuống sông và hàn xương liên thân đốt lối sau tại Bệnh viện Trung ương Thái Nguyên từ tháng 1/2019 đến hêt tháng 31/12/2020.

\section{II. ĐỐI TƯƠ'NG VÀ PHƯƠ'NG PHÁP NGHIÊN CỨU}

2.1. Đối tượng nghiên cứu. Nghiên cứu 43 bênh nhân được chẩn đoán là HOSTL và được điều trị phẫu thuật bằng phương pháp cố định cột sống và hàn xương liên thân đốt thắt lưng tại bệnh viện trung ương Thái Nguyên từ 01/2019 đến $31 / 12 / 2020$.

2.2. Phương pháp nghiên cứu: Nghiên cứu mô tả

\section{KẾT QUẢ NGHIÊN CỨU}

\section{1 Đặc điểm chung của bệnh nhân}

\begin{tabular}{|c|c|c|c|}
\hline \multicolumn{2}{|c|}{ Đặc điểm } & \multirow{2}{*}{$\begin{array}{l}\text { Số beệnh } \\
\text { nhân (n) } \\
4\end{array}$} & \multirow{2}{*}{$\begin{array}{c}\text { Tỉ lệ(\%) } \\
9,30 \\
\end{array}$} \\
\hline \multirow{4}{*}{ Tuổi } & $31-40$ & & \\
\hline & $41-50$ & 8 & 18,6 \\
\hline & $51-60$ & 16 & 37,2 \\
\hline & $>60$ & 15 & 34,9 \\
\hline \multirow{3}{*}{ Giới } & Nam & 11 & 25,6 \\
\hline & Nũ̃ & 32 & 74,4 \\
\hline & óng số & 43 & 100 \\
\hline
\end{tabular}

Nhận xét: Tỷ lệ nữ/nam là 2,91, tuối trung bình mắc phải của bệnh nhân là $56,53 \pm 11,79$, lớn nhất là 79 tuổi, nhỏ nhất là 31.

\subsection{Triệu chứng cơ năng}

\begin{tabular}{|c|c|c|c|}
\hline \multicolumn{2}{|c|}{ Triệu chứng } & Số BN & Tỷ lệ (\%) \\
\hline \multicolumn{2}{|c|}{ Đau lưng } & 43 & 100 \\
\hline Dau lưng lan & 1 bên & 25 & 58,1 \\
\cline { 2 - 4 } xuống chân & 2 bên & 10 & 23,3 \\
\hline \multirow{4}{*}{ Đau cách hồi i } & $<100 \mathrm{~m}$ & 11 & 25,6 \\
\cline { 2 - 4 } & $100-500 \mathrm{~m}$ & 10 & 23,3 \\
\cline { 2 - 4 } & $>500$ & 11 & 25,6 \\
\cline { 2 - 4 } & Không & 11 & 25,6 \\
\hline
\end{tabular}

Nhận xét: $100 \%$ bệnh nhân có đau lưng, đau lan xuống chân $81,4 \%$ chủ yếu là đau 1 bên chân $(58,1 \%)$. 74,4\% bệnh nhân có dấu hiệu đau cách hồi thần kinh.

\begin{tabular}{|c|c|c|c|}
\hline \multicolumn{3}{|c|}{ Triệu chứng thực thể | Số BN $\mid$ Tỷ lệ (\%) } & Tỷ lệ (\%) \\
\hline Co cứng & cơ cạnh sống & 36 & 83,7 \\
\hline \multirow{3}{*}{ Lasèc } & $<30^{\circ}$ & 10 & 23,3 \\
\hline & $30-70^{0}$ & 23 & 53,4 \\
\hline & $>70^{\circ}$ & 10 & 23,3 \\
\hline
\end{tabular}




\begin{tabular}{|c|c|c|c|}
\hline \multirow{2}{*}{$\begin{array}{c}\text { Đánh } \\
\text { giá sức }\end{array}$} & $0 / 5$ & 1 & 2,3 \\
\cline { 2 - 4 } cơ & $3 / 5$ & 2 & 4,7 \\
\cline { 2 - 4 } & $4 / 5$ & 1 & 2,3 \\
\cline { 2 - 4 } & $5 / 5$ & 39 & 90,7 \\
\hline \multicolumn{2}{|c|}{ Teo cơ } & 8 & 18,6 \\
\hline \multicolumn{2}{|c|}{ Rối loạn cơ tròn } & 1 & 2,3 \\
\hline
\end{tabular}

Nhận xét: Co cứng cơ cạnh sống gặp ơ $83,7 \%$ bệnh nhân, $76,7 \%$ bệnh nhân có dấu hiệu Lasègue dương tính; 9,3\% có rối loạn vận động, 18,6\% bệnh nhân có teo cơ, 2,3\% bệnh nhân có rối loạn cơ tròn.

3.4. Phân loại hep ống sống trên phim MRI

\begin{tabular}{|c|c|c|}
\hline $\begin{array}{c}\text { Phân loại hẹp ống } \\
\text { sống }\end{array}$ & Số BN & $\begin{array}{c}\text { Tỷ lệ́ } \\
\text { (\%) }\end{array}$ \\
\hline Hẹp nhẹ & 8 & 18,6 \\
\hline Hẹp vừa & 22 & 51,2 \\
\hline Hẹp nặng & 13 & 30,2 \\
\hline Tổng & $\mathbf{4 3}$ & $\mathbf{1 0 0}$ \\
\hline
\end{tabular}

Nhận xét: $51,2 \%$ bệnh nhân hẹp vừa, đường kính trước sau ống sống trung bình $8,10 \mathrm{~mm}$.

3.5. So sánh điểm VAS trước mổ và khi ra viện

\begin{tabular}{|c|c|c|}
\hline & Trước mố & Sau mố \\
\hline $\begin{array}{c}\text { Mức độ đau trung } \\
\text { bình (Tính theo } \\
\text { thang điểm VAS) }\end{array}$ & $6,79 \pm 1,036$ & $4,14 \pm 0,86$ \\
\hline
\end{tabular}

Nhận xét: Có sư cải thiện mức độ đau sau mổ so với trước mổ với mức cải thiện trung bình là 2,65 $\pm 1,02$ (Khoảng tin cậy $95 \%$ từ 2,34 đến $2,97)$. Sự thay đổi có ý nghĩa thông kê $p<0,001$.

3.6. Đánh giá kêt quả khi ra viện theo thang điểm JOA

\begin{tabular}{|c|c|c|}
\hline Tiêu chí & Số BN & Tỷ lệ (\%) \\
\hline Tốt & 33 & 76,7 \\
\hline Trung bình & 9 & 20,9 \\
\hline Xấu & 1 & 2,3 \\
\hline Tống & $\mathbf{4 3}$ & $\mathbf{1 0 0}$ \\
\hline
\end{tabular}

Nhận xét: Đánh giá kết quả sau mố theo JOA: mức độ tốt có 33/43 bệnh nhân (chiếm $76,7 \%$ ); trung bình $9 / 43$ (chiếm 20,9\%) và xấu 1/43 bệnh nhân (chiếm 2,3\%).

\section{BÀN LUÂ̂N}

Tỷ lệ Nữ/Nam là 2,91. Trung bình tuổi mắc phải của bệnh nhân là $56,53 \pm 11,79$, lớn nhất là 79 tuổi, nhỏ nhất là 31 . Chủ yếu nằm ở nhóm từ 50 tuổi trở lên (chiếm tới 72,1\%). Nhóm tuổi từ 30 đến 49 chiếm 28,9\%. Theo Hoàng Gia Du[2], tỷ lệ nữ/nam là 1,3; tuổi trung bình là $53,5 \pm 15,2$ (2018 trượt L4/15). Tương xứng với tác giả Farrokhi, M. R. và cộng sự (2018) tỷ lệ nữ/nam là 2,67; độ tuổi trung bình là 58,35 $\pm 9,03[6]$. Tuy vậy nhóm tuổi trên 50 vẫn chiếm nhiều nhất và nữ giới vẫn chiếm nhiều hơn nam giới và đa phần bệnh nhân làm nông nghiệp (53.5\%). Có thể do nước ta là một nước đang phát triển, kinh tễ nông nghiệp là chủ yếu nên phụ nữ phải làm việc nặng ảnh hưởng đến cột sống nên tỷ lệ nữ nhiêu hơn nam giới.

Co cứng cơ cạnh sống là phản ứng chống đỡ của cơ thể với tác nhân đau, chúng tôi gặp $36 / 43(83,7 \%)$ bệnh nhân. Phù hợp với nghiền cứu của Nguyến Vũ [5] là 72,1\%; Lê Văn Công [1] là $92,6 \%$.

Dấu hiệu kích thích rễ: đây là triệu chứng đánh giá khách quan sự chèn ép thần kinh. Nghiên cứu của chúng tôi thấy dấu hiệu Lasègue dương tính trong 33/43 (76,7\%) số bệnh nhân trong đó $23,3 \%$ Lasègue $<30^{\circ}, 53,4 \%$ Lasègue $30^{\circ}-70^{\circ}$. Kết quả này tương đương với Nguyễn Vũ [8] (2015) là 87,7\%; Nguyễn Hiền Nhân [4] (2017) là 76,9\%.

Rối loạn cảm giác: là tổn thương xuất hiện ở giai đoạn nặng hơn. Thường khởi phát với triệu chứng tê bì, sau đó bệnh nhân giảm hoặc mất cảm giác theo đường đi của rễ tổn thương. Đây là triệu chứng có giá trị trong chẩn đoán định khu tổn thương. Trong nghiên cứu chúng tôi gặp: $86 \%$ có tê bì chân, $1 / 43(2,7 \%)$ có tê bì và giảm cảm giác 2 chân. Nghiên cứu của Hoàng Gia Du [2] có tê bì (93,3\%), rối loạn cảm giác $3,3 \%, 6,7 \%$ gặp cả 2 biểu hiện trên; Theo Nguyên Vũ [5] rối loạn cảm giác $67,8 \%$.

Rối loạn vận động và rối loạn cơ tròn: khi có dấu hiệu rối loạn vận động và rối loạn cơ tròn là bệnh đã diễn tiến đến giai đoạn nặng và hầu hết các trường hợp đều phải can thiệp phẫu thuật. Nghiên cứu này thấy có $2 / 43(4,7 \%)$ bệnh nhân có sức cơ đo được ở mức $3 / 5,1 / 43(2,3 \%)$ sức cơ $4 / 5$, có 1 bệnh nhân sức cơ 2 chân $0 / 5$ và kèm theo có rối loạn cơ tròn. Nghiên cứu của Lê Văn Công [1] sức cơ 4/5:14,8\%, 3/5 là 1,9\%, không có bệnh nhân nào có sức cơ $0 / 5$; Nguyễn Hiền Nhân [4] có $6 / 39$ có sức cơ 4/5, 1 trường hợp có sức cơ $2 / 5$.

Đường kính trước sau ống sống trung bình là $8,10 \pm 2,20 \mathrm{~mm}$, lớn nhất là $12,0 \mathrm{~mm}$, nhỏ nhất là $4,1 \mathrm{~mm}$, tương đồng với tác giả Lê Văn Công $(9,00 \pm 2,11 \mathrm{~mm})$ [1]; Vũ Minh Hải $(8,4 \pm 2,1)[3]$.

Khi bệnh nhân xuất viện, kết quả phẫu thuật ở mức tốt 33 ca $(76,8 \%)$, trung bình 9 ca $(20,9 \%)$, xấu 1 ca $(2,3 \%)$. Mức độ đau giảm đáng kể so với trước mổ. VAS trung bình trước mổ 6,79 $\pm 1,04$, sau mổ 4,14 $\pm 0,86$ mức độ cải thiện trung bình là $2,65 \pm 1,02$ (Khoảng tin cậy $95 \%$ từ 2,34 đến 2,97$)$. Sự thay đối này có ý nghĩa thống kê $p<0,001$.

Kết quả này tương đương với nghiên cứu của 
Kiều Đình Hùng (2010) có mức tốt 79,2\%, trung bình 18,8\%, xấu 2,0\%; Nguyễn Hiền Nhân (2019) có mức tốt $69,2 \%$, khá và trung bình $30,8 \%$ [4].

\section{KẾT LUẬN}

Hiện nay xu hướng điều trị HOSTLC là can thiệp tối thiểu giải phóng chèn ép. Tuy vậy, phẫu thuật giải phóng chèn ép, hàn xương liên thân đốt và cố định bằng nẹp vít qua cuống lối sau vẫn là phương pháp kinh điển trong điều trị HOSTLC và hiện tại đang được áp dụng phổ biến tại nhiều cơ sở kết quả điều trị tốt đạt $76,8 \% \%$, tỷ lệ biến chứng sau mổ thấp và không có tử vong sau mổ.

\section{TÀI LIÊU THAM KHẢO}

1. Lê Văn Công, Phạm Trịnh Quốc Khanh, Nguyển Văn Lâm (2018), Kết quả điều trị hep ống sống thắt lưng-cùng do thoái hóa bằng phẫu thuật giải ép kết hợp hàn xương liên thân sống tại
Bệnh viện quân Y 121 năm 2016-2017, Bệnh viện quân Y 121, TP Cần Thơ.

2. Hoàng Gia Du (2018), "Đánh giá kết quả điều trị trượt đốt sống thắt lưng L4L5 bắng phẫu thuật lấy đĩa đệm, cố định cột sông và ghép xương liên thân đốt". Tạp trí Y học Việt Nam, 465(2), tr.30-35.

3. Vũ Minh Hải (2016), "Kết quả điều trị phẫu thuật hẹp ống sông thắt lưng tại bệnh viện Đại học Y Thái Bình". Y họ Việt Nam, 2, tr.143-147.

4. Nguyến Hiền Nhân, Nguyê̂n Tuấn Tài, Trinh Quốc Minh, et al (2019). "Đánh giá sau phâuu thuật hẹp ống sống thắt lưng đa tầng do thoái hóa bằng phương pháp hàn xương liên thân đốt lối sau tại bệnh viện Trưng Vương". Y học TP Hồ Chí Minh, 23 (6), tr.28-33.

5. Nguyễn Vũ (2015), Nghiên cứu điều trị trượt đốt sông thắt lưng bằng phương pháp cố định cột sống thắt lưng qua cuống kết hợp hàn xưởng liển thân đốt, Luận văn tiến sỹ, Đại học Y Hà Nội.

6. Farrokhi M. R., Yadollahikhales G., Gholami M. (2018), "Clinical Outcomes of Posterolateral Fusion Versus Posterior Lumbar Interbody Fusion in Patients with Lumbar Spinal Stenosis and Degenerative Instability", Pain Physician, 21 (4), pp. $383-40$

\section{ĐÁNH GIÁ TÍNH AN TOÀN VÀ HIÊUU QUẢ CỦA VIÊN TRĨ THIÊN DƯỢC TRÊN BÊNH NHÂN TRĨ் Nô̂I Độ II CÓ CHẢY MÁU THEO CÁC THỂ BÊ̂NH Y HỌC CỔ TRUYỀN}

\section{Lê Thị Minh Phương1, Lê Mạnh Cường², Phạm Đức Huấn ${ }^{1}$, Phạm Bá Tuyến ${ }^{3}$}

\section{TÓM TẮT}

Muc tiêu: Đánh giá tính an toàn và hiệu quả của viên Trĩ Thiên Dược trên các bệnh nhân trĩ nội độ II có chảy máutheo các thể bệnh $Y$ học cổ truyền. Đối tượng và phương pháp: Phân tích gộp dựa trên dữ liệu bệnh nhântừ 2 thử nghiệm lâm sàng giai đoạn II và III ngâuu nhiên, mù đôi, có đối chứng. Kết quả: Viên Trĩ Thiên Dược an toàn và có tác dụng làm giảm rõ rệt các triệu chứng như đau rát hậu môn, đại tiên ra máu, xung huyết búi trĩ trên bệnh nhân nghiển cứu ở cả 3 thể bênh là thể huyết ứ, thấp nhiêt và khí huyết hư, trong đó, hiệu quả rõ rệt nhất trên thể thấp nhiêt. Kết luân: Viên Trĩ Thiên Dược có tác dung điều trị bệnhtrĩ nộ̉i độ II có chảy máu trên các thể lâm sàng $\mathrm{YHCT}$. Dược.

Từ khóa: Trĩ nội độ II có chảy máu, viên Trĩ Thiên

\footnotetext{
${ }^{1}$ Trường Đại học Y Hà Nội

²Bệnh viện Y học cổ truyền Trung Ương,

${ }^{3}$ Bệnh viện Y học cổ truyền Bộ Công An

Chịu trách nhiệm chính: Lê Mạnh Cường;

Email: drcuong68@gmail.com

Ngày nhận bài: 4/11/2021

Ngày phản biện khoa học: 30/11/2021

Ngày duyệt bài: 21/12/2021
}

\section{SUMMARY \\ EVALUATING THE SAFETY AND EFFICACY OF TRI THIEN DUOC CAPSULE IN THE TREATMENT OF BLEEDING STAGE II INTERNAL HEMORRHOIDS ACCORDING TO TRADITIONAL MEDICAL SYNDROMES}

Objectives: To evaluate the safety and efficacy of Tri ThienDuoc capsule in the treatment of bleeding stage II internal hemorrhoids according to traditional medical syndromes. Subjects and method: Metaanalysis of individual patient data from 2 randomized, double-blind, placebo-controlled, phase II and III clinical trials. Results: Tri ThienDuoc was safe and reduced symptoms such as anal itching, rectal bleeding, and thrombosed hemorrhoids in patients with three syndromes, including blood stasis, dampheat, and a deficiency of qi and blood, whose most pronounced effect was on the damp-heat syndrome. Conclusion: Tri ThienDuoc was effective in reducing symptoms of Bleeding stage II internal hemorrhoids according to traditional medical syndromes.

Key words: Bleeding stage II internal hemorrhoids, Tri ThienDuoc.

\section{I. ĐẶT VẤN ĐỀ}

Trĩ nội là bệnh lý vùng hậu môn trực tràng phổ biến, có tỉ lệ mắc cao trên $55 \%$ dân số nước 